\title{
Reflective Blogfolios in the Language Classroom: Impact on EFL Tertiary Students' Argumentative Writing Skills and Ways of Knowing
}

\author{
Ammar, Abdullah Mahmoud Ismial \\ Curriculum \& Instruction Dept, Faculty of Education, Sohag University, Egypt \\ E-mail: abdallai2000@yahoo.com
}

Doi:10.7575/aiac.alls.v.7n.5p.247

URL: http://dx.doi.org/10.7575/aiac.alls.v.7n.5p.247
Received: 23/07/2016

Accepted: 16/08/2016

\begin{abstract}
The emerging paradigm shift in educational contexts from walled classroom environments to virtual, hybrid, blended, and lately personal learning environments has brought about vast changes in the foreign language classroom practices. Numerous calls for experimenting with new instructional treatments to enhance students' language performance in these new learning environments have been voiced by researchers and language educators in different settings. The current study aimed at investigating the impact of using reflective blogfolios in teaching argumentation to EFL tertiary students on their argumentative essay writing skills and ways of knowing. As well, the study investigated the relationship between student's ways of knowing and their argumentative writing capabilities. The participants of the study were fifty one EFL tertiary students in the Emirati context. Two assessment instruments were used, including a ways-of-knowing scale and a rubric for tapping EFL students' argumentative writing skills. Results of the study indicated that using reflective blogfolios in the foreign language classroom brought about significant changes in EFL tertiary students' argumentative writing skills and their ways of knowing. Results of the study also indicated that connected ways of knowing were better predictors of EFL tertiary students' argumentative writing performance than separate ways of knowing. Details of the instructional intervention, the assessment instruments, results of the study, implications for foreign language instruction in virtual learning environments, and suggestions for further research are discussed.
\end{abstract}

Keywords: Reflective blogfolios, argumentative writing skills, ways of knowing

\section{Introduction}

The last few years have witnessed a revived interest in argumentation skills in educational settings as well as in everyday language use situations. This interest is not restricted to language education programs, but rather extends to different disciplines and different academic discourse communities. The paradigm shift towards virtual learning environments coupled with the increasingly growing explosion of information has added momentum to this accent on argumentation skills.

A number of factors stand behind this heated interest in argumentation capabilities in general and argumentative essay writing skills in particular. First, as Styslinger and Overstreet (2014) stated, argumentation is a core standard for participation in a democratic society. Second, as Andrews (2009) argues, argumentative writing has been considered the most highly prized type of academic discourse. Third, the construction of arguments is considered a core discursive activity of science. As explained by Osborne et al (2004), assessing alternatives, weighing evidence, interpreting texts, and evaluating the potential validity of claims are all seen as essential components in constructing scientific arguments. Likewise, argumentation is considered an essential vehicle for developing critical thinking skills in different disciplines (Kolour, 2015; Fahim \& Hashtroodi, 2012; Wingate, 2011; Facione, 2009).

In academic settings and language learning contexts, success or failure of learning endeavors has been attributed in part to the quality of students' argumentation skills (Andrews et al., 2004). Empirical research findings and conclusions thereof carry evidence that developing students' argumentation skills often lead to improved academic performance. For example, enhancing students' written argumentation resulted in prompting their ability to acquire knowledge (Schwarz et al, 2003; Zohar \& Nemet, 2002) and enhanced their scientific thinking capabilities (Shanahan, 2004). Similar conclusions have been made regarding the impact of promoting argumentative skills on enhanced comprehension (De La Paz, 2005), increased intrinsic motivation and better problem-solving performance (Chinn, 2006).

Yet, despite this significance of argumentation skills in different disciplines, argumentative essay writing is a much neglected mode in the language curriculum. Research evidence from different language learning settings shows that students are neither effective in using argumentative writing strategies and adapting them to the communicative circumstances nor in creating convincing written arguments (Ferretti et al, 2009; Lee, 2008; Salahu-Din, Persky \& Miller, 2008; Grahem \& Perin, 2007; Nussbaum \& Kardash, 2005; Hirose, 2003; Van-Eemeren et al, 2002). In the 
Emirati context of FL instruction, similar conclusions have been stated by educators and language researchers. Students, as Sayed (2012) stated, do not take argumentative writing seriously and generally lack motivation to write in the target language. Eldaly (2012) expressed a similar concern regarding the scarcity of research on persuasive and argumentative writing of foreign language learners.

The observations of the researcher of the current study come in line with these conclusions. Whether in the Debate \& Discussion course or in Writing I \&II where argumentative writing is taught as part of the courses, students showed incompetence in debating controversial topics or in arguing convincingly with one another. Very often than not arguments turned into fights and arguers targeted each other personally rather than tried to negotiate ideas, see issues from different perspectives, and reach informed collective conclusions accordingly. This in turn had its ramifications whether in these or other courses taught in the English program. Communication in the classroom was often interrupted due to inability to connect with other students or to argue more convincingly.

This seems very detrimental to what Schneider and Ingram (2007) referred to as "communicative rationality" necessary for establishing healthy classroom learning conditions. According to Schneider and Ingram, communicative rationality emerges from discourse where people reason together to arrive at the best possible collective decision or stance. It requires that all players be at the table; there be no power or status differentiation; and all have the chance to participate equally in the discussion.

Another ramification of argumentative incompetence that relates to the communicative rationality issue mentioned above is "communication hierarchy" or dominance (Shanahan, 2004). Communication in the language classrooms often follows a hierarchical pattern where good arguers and better communicants dominate the language learning scene while students with poor argumentation skills lag way behind and miss the very chance to be part of the classroom dialogue going therein. This, in turn, is likely to affect not only their communication skills but as well their overall language performance and academic achievement.

\subsection{Statement of the Problem}

The problem of the study, as discussed in the above introduction, lies in the poor argumentative writing performance of EFL tertiary students, though argumentative essay writing is a core component in their foreign language education program. The problem is more intricate with the emerging paradigm shift towards virtual and personal learning environments, where EFL students are more likely to interact with wider circles of audience from different cultures, different educational backgrounds, and different fields of study. As the ways of knowing and argumentation mechanisms in these contexts might be different from the ones EFL students are able to activate, they might be in a disadvantage regarding how to competently interact, communicate, or argue with peers in these new learning contexts.

The current study proposes an instructional framework for using reflective blogfolios in EFL writing classes to promote tertiary students' argumentative writing skills. It is driven by the scarcity of evidence in the existing language literature regarding the relationship between EFL students' ways of knowing and the quality of their argumentative essay writing as well as the growing need to experiment with new technological applications in language learning settings. The impact of the proposed instructional intervention on students' argumentative essay writing as well as their ways of knowing was investigated. The relationship between students' argumentative writing capabilities and their ways of knowing was studied as well.

\subsubsection{Questions of the Study}

Three main research questions were tackled, including:

a) Is there any statistically significant impact of reflective blogfolios on EFL tertiary students' argumentative writing skills?

b) Is there any statistically significant impact of reflective blogfolios on EFL tertiary students' ways of knowing?

c) Is there any significant relationship between EFL tertiary students' ways of knowing and their argumentative essay writing skills?

\subsection{Significance of the Study}

Significance of the study stems from a number of considerations as follows:

a) Argumentative writing is a much neglected mode of writing in most language study programs. As a basic type of academic discourse in different disciplines, let alone foreign language studies, argumentation plays a determinant role in student achievement and engagement. Learning environments are often dominated by individuals with better argumentation capabilities while those with limited capabilities are left out or behind with fewer chances for participation in the classroom dialogue going therein. This, in turn, would negatively impact their engagement and achievement in academic settings. Developing students' argumentation capabilities would help them function much better not only in argumentative writing but as well in other language learning settings.

b) The study deals with argumentative writing skills in virtual learning environments that have different rules from the ones practiced by students in the traditional language classroom. With the increasing migration in educational settings towards virtual and personal learning environments, a need is felt for investigating argumentation mechanisms and processes in these new environments to see how far they might be different from the ones prevailing in the traditional classroom settings. If students are not adequately prepared to manage within these new environments, they would be in a disadvantage when interacting with peers from different cultural and disciplinary backgrounds that might have argumentation mechanisms and ways of knowing that are different from theirs. 
c) The study proposes an instructional framework for using reflective blogfolios for enhancing the argumentative writing skills of EFL tertiary students that combines together the privileges of three sub-themes; namely, blogging, portfolios, and reflective practice. In so doing, the study takes blogging techniques a step forward through changing them from solitary action by individual students to a collaborative learning platform governed by principles of group authorship, monitoring and reflection, continuous development overtime, and mutual support.

d) Attention is given to ways of knowing as a variable with potential impact on students' argumentation capabilities. This variable has not been given due attention in foreign language research literature. Investigating the relationship between ways of knowing and argumentation might help language teachers better manage argumentation situations and adjust based on students' preferred ways of knowing and approaching argumentative tasks. This applies to ways of knowing in argumentative situations as well as foreign language learning settings in general. When instructional techniques of language teachers are commensurate with their students' preferred ways of knowing, they can better connect with them, which in turn would yield better learning gains.

\subsection{Review of Literature}

The paradigm shift from traditional walled classroom environments towards synchronous communication and internetbased language learning environments has brought about vast changes in language learning settings and practices that led, in turn, to alterations in the argumentation processes and techniques therein. First, as Jonassen and Kim (2010) and Chen and She (2012) argue, online learning environments provide excellent support for students to construct their explanations and knowledge negotiation processes in argumentation. Second, unlike traditional learning settings, technology-based environments, as Maftoon et al (2014) argue, provide interdisciplinary and multicultural learning opportunities to students, which in turn avail them chances to see thing from different perspectives and integrate knowledge from different disciplines in ways that were never possible in traditional learning environments. Moreover, according to Pearson et al (2009) and Hall (2009), they availed increased opportunities for students to access learning support and experiences outside of the traditional classroom theatre.

This paradigm shift induced vast changes in language learning settings and pedagogical practices thereof. Language learning is no longer confined within walled classrooms under teachers' patronization and control. Rather, it has been broadened to contexts where learners find themselves overwhelmed by a plethora of language learning resources and experiences rarely made available to them in traditional learning environments. The "one-size-fits-all" approach prevailing traditional learning environments has been abandoned for more accent on multiplicity and pluralism in learning approaches and resources (Miller et al, 2008). This, in turn, has led to a corresponding shift in pedagogy towards connectivist approaches (Siemens, 2008) and personalized learning environments--PLEs (Attwell, 2007), where there are constant opportunities for collaboration, sharing, and mixing.

The remarkably increasing adoption and adaptation of web 2.0 and Web 3.0 tools in educational settings have brought possibilities and expectations of flexibility and personalization of learning. According to Pearson et al (2009), the new learning environments include and bring together all learning, including informal learning, workplace learning, learning from the home, as well as learning through engagement in formal educational programs. As Lubensky (2006) argues, it is based on the idea that learning will take place in different contexts and situations and will not be provided by a single learning provider.

Four basic characteristics, Lubensky (2006) argues, are stressed in these environments. These include individual control over tools and content, aggregation of content, integration of services, and no space and time limits. The result, according to Hall (2009), Ebner (2009) and Mason and Rennie (2007), is more empowerment of learners to rethink the places and spaces they can represent themselves and positively extend their personal learning experiences.

The question that arises here is how foreign language learners long educated in traditional learning contexts manage the shift in argumentative situations in these learning environments, which as Barnett (2008) states, have different rules from traditional academic contexts. A number of features make this shift quite uneasy. First, it's a shift from depending on one source of knowledge, be it the teacher or the textbook, to drawing on a multiplicity of knowledge sources. Second, it's a shift from interaction with learners from the same cultural background to interaction with learners from culturally diversified contexts with all likelihood of not only having different but also contradicting views and values. Third, it's a shift from exclusively interacting with members of the same learning community (COL), to interaction with members of other communities such as the community of practice (COP) and the community of interest (COI) (Chatti et al, 2010; So \& Brush, 2008; Liu et al, 2007; Shea, 2006; Palloff \& Pratt, 2005)

Most importantly, it's a shift from perceiving learners as consumers of knowledge to learners as providers and constructors of own knowledge and understandings. Here, learners learn through their connections, constructions, and communications of those knowledge constructions to those in their social connections or networks (Siemens, 2008). In such a context, as Miller et al (2008) argue, ways of knowing and knowing processes play determinant roles. Again, the question that arises here is how argumentation might be affected by the multitude of ways of knowing that members of the new learning community are likely to deploy in argumentative settings.

\subsubsection{Ways of Knowing \& Argumentation}

According to Schneider and Ingram (2007), 'ways of knowing' refers to " how one interprets the elements in a given situation and makes sense of the relationships among them" (P.2). Ways of knowing, Feldman et al (2006) argue, are different from knowledge in the sense that they emphasize the active dimension of knowing a problem or the way it is experienced, investigated, and acted upon. The term "ways of knowing” first appeared in Belenky et al's (1997) 
epistemic development model as part of the procedural knowledge stage, wherein learners start applying objective procedures for obtaining and communicating knowledge.

These ways of knowing were found to impact students' academic performance and the way they approach learning tasks (Schommer-Aikins \& Easter, 2006). As well, they were found to impact the quality and the quantity of responses students are likely to provide in educational settings (Nassbaum \& Kardash, 2005). Accordingly, a number of calls have been voiced by educators and researchers that ways of knowing be a core component of the school curriculum in different fields of study (Barnhardt \& Kawagley, 2005; Schommer-Aikins \& Easter, 2006; Carter, 2007; Millet et al, 2008; Khine \& Hayes, 2010).

In the language learning contexts, two ways of knowing have been related to argumentation: separate and connected ways of knowing. Separate procedural knowledge, according to Belenky et al (1997, cited in Khine \& Hayes, 2010: 106), refers to using critical thinking to play the doubting game where arguers look for loopholes, factual errors, logical contradictions, omission, or contrary evidence to refute the opponents' arguments. They tend to take a more critical and argumentative stance to learning and enjoy a sense of detachment as required in critical thinking, scientific method, and textual analysis. Connected knowers, on the other hand, play the believing game, learn through empathy and nonjudgmental stances, and tend to learn cooperatively. They are more congenial and more willing to build on the ideas of others. They believe rather than doubt and accept before they challenge (Khine \& Hayes, 2010).

These ways of knowing determine to a great extent students' approaches not only in argumentative situations but also in language learning settings in general. Learners with a strong belief in connected knowing, as described by Gallotti et al (cited in Schommer-Aikins, 2004: 23), "initially attempt to empathize with the knowledge source, take on the source's perspective, and understand the point being made. Only after understanding the point are they ready to be more critical. In contrast, learners with a stronger belief in separate knowing take an adversarial perspective first. Functioning as a devil's advocate, they question, doubt, and wait for evidence before they attempt to deeply understand the information".

Clinchy (1996, cited in Khine \& Hayes, 2010:106) differentiated between connected knowing and subjectivism with the former referring to the effort to listen to and understand the other, while the latter referring to silencing the voice of the other. Connected knowing is based on the assumption that everyone's opinion is right for him or her. Connected knowers don't necessarily as a result of their empathetic listening to others finally agree with them (Khine \& Hayes, 2010).

Literature shows that individuals in different cultures have preferences in terms of their ways of knowing (Hofer, 2008) and that cultural variables have impacts on students' argumentation styles and skills (Kachru, 2005). For example, in a contrastive study, Liu (2009) found differences between American and Chinese students' argumentative discourse due to cultural factors. American students made their personal stances extremely explicit at the very beginning of the argumentative essays due to beliefs in individualism. Chinese students, guided by values of collectivism, avoided absolute arguments and utilized indirect strategies in presenting their theses.

In a similar study, Su-Yuen \& Rubin (2000) evaluated the impact of collectivism and individualism on the argumentative writing of Chinese and North American students. Differences in argumentative writing were attributed to socialized discourse conventions. Taking the conclusions of these studies together, one would argue that differences in argumentative styles and processes can be attributed to differences in individuals' ways of knowing, an area that has not heretofore been investigated in the existing literature especially in the foreign language learning contexts. Moreover, the nature and path of the interaction between argumentative writing and ways of knowing have not yet received due attention. Exploring the causal relationship between the two variables might help identify the path of impact and accordingly their learning prerequisites.

Driven by a felt need to enhance argumentative writing performance of EFL students in virtual learning environments and the scantiness of research on the relationship between students' argumentative skills and their ways of knowing, the current study proposes an instructional intervention based on using reflective blogfolios in the foreign language writing classroom. The impact of the intervention on students' argumentative writing skills and their ways of knowing has been investigated. Likewise, the relationship between argumentation capabilities and ways of knowing has also been studied as discussed in the lines below.

\section{Method}

\subsection{Participants}

The current study involved 51 students (28 females and 23 males) taking a writing course in the ADU University of the United Arab Emirates during the academic year 2013-2014. As ADU is a culturally diverse educational context, students come from different countries, including Egypt, Emirates, India, Iran, Jordan, Lebanon, Oman, Pakistan Palestine, Somalia, Spain, the Sudan, and Syria. All participants were competent in using different tools of the learning management system (Blackboard) adopted by the university. Each participant had one or more smart devices (smart phones, ipads, tablets, laptops) with internet access both on campus and at home.

\subsection{Design of the Study}

The quasi-experimental approach was utilized in the current study. Participants were included in a one-group experimental treatment with pre-post assessment procedures. An instructional framework for using reflective blogfolios in EFL tertiary writing classes was field-test on a group of 51 participants. Initially and post-instructionally, students were assessed for their argumentative writing skills and ways of knowing. 
In the current study, a suggested instructional framework for using "reflective blogfolios" in teaching argumentative writing was field-tested on $51 \mathrm{EFL}$ tertiary students in the Emirati context. Ananyeva (2014) defined Blogfolios as "interactive blog-based portfolios used to record students' learning progress and assess students learning performance in the educational context for a long period of time" (p.22). They incorporate " a purposeful and selective collection of work that tells the story of reflection and self-assessment and provides authentic evidence of the individual's efforts, skills, abilities, achievement, and contributions over time" (Lin et al, 2007: 858).

The term "blogfolios" was adopted in this study to give a different sense from "blogs". Defined by Herring et al (2004) and Boyd (2006), "blogs" (weblogs) involve producing frequently modified web-based digital content with the intention of sharing it asynchronously with a conceptualized audience. Reflective blogfolios here are used as an online instructional framework for establishing a community of arguers, where students can exchange ideas, negotiate controversial topics, defend, refute, convince, and insightfully reflect on their and others' arguments. The ultimate aim was to strengthen their argumentative skills through broadening their horizons, helping them see things from different perspectives, and embracing differences more constructively.

The basic tenets of the "reflective blogfolios" experience included the following procedures:

1. Students were guided to create blog accounts and share these amongst themselves so that they be able to follow one another for exchanging ideas and negotiating issues.

2. Each week, an argumentative topic was suggested for writing. Students were instructed to write their ideas individually and then post them on their blogs.

3. In writing their initial ideas, students were guided into using the boomeranging technique wherein they start with an assumed stance and generate arguments to support this stance. Then they take an adversial stance on the same topic and argue against their very ideas. Finally, they were asked to juxtapose their ideas-both for and against the argumentative topic - for more logicality and convincingness. The purpose was to tap their ways of knowing, both connected and separate.

4. Then, individual students write drafts of their argumentative essays and post them on their individual blogs.

5. Students read each other's blogs and write their comments - be it in the form of more arguments, counterarguments, support with evidence, reasons...etc.

6. The process continues until each student has read and made comments on all classmates' written drafts.

7. Once the process of reading and commenting is over, individual students reconsider drafts in light of the feedback posted by their peers and the new ideas/arguments proposed during this phase of idea generation/negotiation.

8. The next phase, students take their generated arguments to the classroom and indulge in a session of face-to-face argumentation and debating about the topic under consideration. They are guided throughout the process of structuring genre-specific argumentation with statement of resolution (thesis), arguing for or against the topic, supporting arguments with evidence and reasons, and writing suitable introductions and conclusions.

9. The next phase of the process, students assimilate the whole experience, rewrite a second draft of their argumentative essays and post them on their blogs for a further cycle of negotiation and feedback by peers and the instructor.

10. The process of exchanging feedback continues yet expanded to language-related in addition to the content-related feedback.

11. The process of generating arguments, negotiating content with peers and reflecting on written arguments of self and others continues with new argumentative topics suggested each week---a process that lasted for the whole semester.

12. Students were also encouraged to argue on topics of their choice and exchange feedback on their blogs with peers in the writing course as well as with friends from other colleges and majors in ADU. The aim was to extend their blog community to a wider circle of audience.

13. By the end of the semester, students were asked to collect best pieces of argumentative writing that they generated in their blogs throughout the semester, print them out, put them in a blogfolio and be ready to share their experiences in reflective classroom presentations. Students were also encouraged to videotape personal reflections on own and others' blogfolios and attach them to their blog accounts for further feedback from peers and the instructor.

\subsection{Instrumentation}

Two assessment instruments were used in this study to investigate the impact of using reflective blogfolios in teaching writing to EFL tertiary students on their argumentative writing skills and ways of knowing. These included a ways-ofknowing scale and an argumentative writing scoring rubric.

\subsubsection{Ways of Knowing Scale}

EFL tertiary students ways of knowing were assessed via a revalidated form of the Ways-of-Knowing Scale of knight et al. ( 1995). The original form of the scale was revalidated on a group of EFL students in the Emirati context (not included in the current instructional intervention) to ensure its factorial structure, clarity, and validity for use in the Emirati EFL context. The procedure involved administering the scale to 147 students and then running a factor analysis procedure on the scores they obtained, using Varimox Rotation with Eigen values of (1) and a minimum item loading of (.5) or greater. Investigation of the resulting scree plot suggested a two factor solution similar to that of the original scale, with minimum item loadings of .64 . 
Thus, the revalidated form of the scale included 12 items pivoted around two factors representing connected and separate ways of knowing (6 items each). They are Likert Scales type items with 5-point rating scheme ranging from totally agree with the statement " $5 "$ to totally disagree " $1 "$. The current study adopted a scoring scheme different from that employed in the original scale. In the original scale, items representing separate knowing and connected knowing were scored similarly but separately as if they were two separate subscales. In the current study, the separate ways of knowing items were reverse-coded (they were scored on a scale from 1-5 for total agreement " 1 " to total disagreement "5") so that lower scores on the scale indicated higher levels of separate knowing, whereas higher scores reflected higher levels of connected knowing.

\subsubsection{The Argumentative Writing Scoring Rubric}

In assessing the argumentative writing skills of the study participants, the researcher adopted the evaluation framework suggested by Ferretti et al (2009). The framework analyzes the structure of argumentative writing based on the pragmadialectical theory of argumentation. The coding system used to distinguish elements of the argumentative structure included the following items (each scored on a 5-point scale ranging from Really Poor "1" to Outstanding "5".

1. Clarity of the students' thesis or standpoint regarding the argumentative issue,

2. Provision of enough reasons and evidence to support the standpoint,

3. Identification of alternative standpoints (standpoints of other people that the student disagrees with) and reasons behind them,

4. Identification of counterarguments that could be used to undermine the students' standpoints (potential criticism of the students' standpoints and supporting reasons thereof),

5. Provision of rebuttals of the alternative standpoints,

6. Logical and easy-to -follow organization,

7. Introductions that foreshadow what is to follow in the students' presentation of the arguments, and

8. Conclusions that bring together or summarize what the student has written.

\subsubsection{Inter-rater Reliability}

Two raters took part in evaluating the students' argumentative essays. They were trained in scoring the argumentative writing using the Ferretti et al's (2009) pragma-dialectical framework outlined above to ensure consistency in their scoring procedures. By the end of training, inter-rater reliability was calculated. This yielded a coefficient of (.92). The final scores on individual students' argumentative writing were obtained by averaging the scores given by the two raters.

\section{Results of The Study}

For investigating the impact of the reflective blogfolios on EFL tertiary students' argumentative writing skills and ways of knowing, their scores in the pre-post assessments were calculated and tabulated. The Statistical Package for the Social Sciences (SPSS, V.19) was utilized in the statistical treatment to provide answers to the study questions as shown below:

\subsection{Impact of Reflective Blogfolios on Argumentative Writing Skills}

For investigating the impact of using the suggested framework of using reflective blogfolios on developing EFL tertiary students' argumentative writing skills, the mean scores they obtained in the pre-assessment of their argumentative essay writing skills were compared to those of the post assessment. The paired samples t-test procedure was used in judging the statistical significance of the difference between mean scores. Details are outlined in Table (1).

Table 1. Paired samples t-test analysis of the pre-post assessments of EFL tertiary students' argumentative essay writing skills

\begin{tabular}{|c|c|c|c|c|c|c|c|}
\hline & $\mathrm{N}$ & M & SD & $\begin{array}{l}\text { Std Error } \\
\text { mean }\end{array}$ & Df & t-value & Sig. (2-tailed) \\
\hline Pre-assessment & 51 & 24.8039 & 3.52715 & .49390 & \multirow{2}{*}{1,50} & \multirow{2}{*}{16.908} & \multirow{2}{*}{.000} \\
\hline Post-assessment & 51 & 33.4902 & 3.27642 & .45879 & & & \\
\hline
\end{tabular}

As shown in Table (1), a statistically significant difference between the mean scores obtained by EFL tertiary students on the pre-post assessments of their argumentative writing skills does exist. This statistically significant difference is in favor of the post-assessment scores ( $\mathrm{t}$-value $=16.908, \mathrm{P} \geq .05)$. This in turn indicates that the argumentative writing skills of the study sample have improved remarkably due to receiving the instructional treatment. Using reflective blogfolios in the writing classroom has resulted in higher gains in their argumentative writing capabilities.

As reflected by the different items of the scoring framework, EFL tertiary students' engagement in the reflective blogfolios experience positively impacted various aspects of their argumentative writing. They became more competent 
in arguing more convincingly and supporting their arguments with reasons and evidence. Their standpoints were more clearly stated and supported with reasons of different types.

As well, they got more acumen in identifying counterarguments that can be used to undermine their arguments and showed more skillfulness in rebutting their opponents' arguments and alternative standpoints. They became more focused regarding the topic of argumentation and more able to write clear introductions and conclusions. Their abilities to organize argumentative essays and progress smoothly along their arguments improved remarkably. They got experience in weaving their arguments and knitting details in a way that eliminated redundancy and irrelevance.

\subsection{Impact of Reflective Blogfolios on Ways of knowing}

For investigating the impact of reflective blogfolios on EFL students' ways of knowing, their scores in the pre-post assessments were calculated, tabulated, and analyzed. The paired samples t-test procedure was used in judging the statistical significance of the difference between the pre-post assessment mean scores. Details are summarized in table (2).

Table 2. Paired samples t-test analysis of the pre-post assessments of EFL tertiary students' ways of knowing

\begin{tabular}{|c|c|c|c|c|c|c|c|}
\hline & $\mathrm{N}$ & $\mathrm{M}$ & SD & Std Error Mean & Df & t-value & Sig. (2-tailed) \\
\hline Pre-assessment & 51 & 2.5235 & .63893 & .08947 & \multirow[t]{2}{*}{1,50} & \multirow[t]{2}{*}{10.650} & \multirow{2}{*}{.000} \\
\hline Post-assessment & 51 & 3.5980 & .66347 & .09290 & & & \\
\hline
\end{tabular}

Data shown in Table (2) indicate that EFL tertiary students' ways of knowing have changed in the course of the instructional treatment. A statistically significant difference exists between the participants' mean scores in the pre-post assessment of their ways of knowing $(\mathrm{t}=10.650, \mathrm{P} \geq .05)$, favoring the post-assessment results. It should be noticed here that higher scores on the Ways-of-knowing Scale reflect higher levels of connected knowing as outlined above in the "Instrumentation" section.

The pre-assessment scores reflect preferences in their knowledge processes towards detachment and more employment of separate ways of knowing in argumentative settings. Based on the literature surveyed above, when separate knowers argue with one another they prefer to play the devil's advocate. They search for flaws in their opponents' arguments rather than try to understand their standpoints. Their ultimate aim is to convince and be convinced rather than understand and be understood.

By the conclusion of the instructional intervention, the reflective blogfolios experience, their ways of knowing had changed towards more connectedness. Their post-assessment mean score indicates that they started to show more empathy in their argumentation. They tried to understand the logic behind the counterarguments and tried to understand the world from their opponents' vantage point even if they did not agree with them. They started to embrace a multitude of viewpoints people might have on controversial issues rather than seeing the world from a tunneled vision. Putting themselves in the shoes of opponents helped them see things from different angles.

\subsection{Ways of Knowing \& Argumentative Writing Skills}

Since the participants' ways of knowing changed in the course of the instructional treatment towards more connected knowledge, as discussed in the previous section, the researcher investigated the relationship between ways of knowing and argumentative writing both initially and post-instructionally. This aimed at investigating whether changes in their ways of knowing had impacted their argumentative writing capabilities, i.e. whether participants' ways of knowing can predict changes in their argumentative essay writing performance. Regression analysis procedures were used in the statistical treatment (Maxwel \& Delaney, 2004). Ways of knowing were entered as predictors and argumentative essay writing performance as a dependent variable. Results are summarized in Table (3).

Table 3. Regression analysis of the relationship between EFL tertiary students' ways of knowing and their argumentative writing performance

\begin{tabular}{|c|c|c|c|c|c|c|c|c|}
\hline & Model & $\begin{array}{l}\text { Sum of } \\
\text { squares }\end{array}$ & $\mathrm{Df}$ & $\begin{array}{l}\text { Mean } \\
\text { square }\end{array}$ & $\begin{array}{c}\mathrm{R} \\
\text { square }\end{array}$ & $\begin{array}{l}\text { Adjusted R } \\
\text { square }\end{array}$ & $\mathrm{F}$ & Sig. \\
\hline \multirow{3}{*}{$\begin{array}{l}\text { Pre- } \\
\text { assessment }\end{array}$} & Regression & 33.208 & 1 & 33.208 & \multirow{3}{*}{.053} & \multirow{3}{*}{.034} & \multirow{3}{*}{2.763} & \multirow{3}{*}{.103} \\
\hline & Residual & 588.831 & 49 & 12.017 & & & & \\
\hline & Total & 622.039 & 50 & & & & & \\
\hline \multirow{3}{*}{$\begin{array}{l}\text { Post- } \\
\text { assessment }\end{array}$} & Regression & 45.223 & 1 & 45.223 & \multirow{3}{*}{.084} & \multirow{3}{*}{.066} & \multirow{3}{*}{4.508} & \multirow{3}{*}{.039} \\
\hline & Residual & 491.522 & 49 & 10.031 & & & & \\
\hline & Total & 536.745 & 50 & & & & & \\
\hline
\end{tabular}


As shown by data in Table (3), it seems that EFL tertiary students' ways of knowing varied in their ability to predict argumentative writing performance. Close inspection of data from the pre-post assessments reveals that ways of knowing were not able to predict argumentative writing performance in the pre-assessment $\left[\mathrm{F}=2.763, \mathrm{P}=.103, \mathrm{R}^{2}\right.$ $=.053]$. Contrariwise, post-assessment results show ways of knowing as strong predictors of students' argumentation skills $\left[\mathrm{F}=4.508, \mathrm{P}=.039, \mathrm{R}^{2}=.084\right]$. It should be noticed here, as discussed in the previous section, that students' ways of knowing changed in the course of the instructional intervention towards more connected knowing. In the preassessment, students showed more tendency to adopt separate ways of knowing. By the conclusion of the reflective blogfolios experience, the pendulum swung towards more connected knowing.

It seems, based on these results, that connected ways of knowing are better predictors of quality argumentative writing performance than separate ways of knowing. It sounds logical that students who can connect with others, see how peers think and behave, and formulate argumentative stances accordingly to be better arguers. Students with connected ways of knowing showed more skillfulness in arguing more convincingly and an ability to generate more arguments and support these with logic and evidence compared to those with separate ways of knowing. As well, they showed more ability to refute counterarguments that might undermine their stances. The mean score they got on their argumentative essay writing in the post-assessment is significantly higher than that of the pre-assessment, indicating greater argumentation capabilities post-instructionally.

Drawn together, data shown in Table (1), Table (2) and Table (3) reveal three consistent conclusions. First, using reflective blogfolios in teaching argumentative writing to EFL tertiary students resulted in higher gains in their argumentative essay writing performance. Second, their ways of knowing swung due to receiving the instructional treatment towards more connected ways of knowing. Third, changes in the participants' ways of knowing were paralleled by corresponding changes in their argumentative writing abilities, which in turn, indicates that connected ways of knowing are better predictors of quality performance in argumentative writing settings than separate ways of knowing.

\section{Discussion}

It is clear from the results of the study outlined herein that the proposed technique of reflective blogfolios had a significant impact on EFL tertiary students' argumentative writing skills and their ways of knowing. Their argumentative writing skills have improved significantly and their ways of knowing have witnessed reframing in a way that contributed positively to how they approached argumentative writing situations and tasks. This significant impact can be explained in terms of a number of features that reflective blogfolios availed in a way that has rarely been possible in traditional classroom settings or in the traditional daily routine writing in blogs.

The first of these features is the collaborative authorship experience that EFL students had while writing in their reflective blogfolios. Students worked together, negotiated ideas more constructively, and provided support to each other. As ideas were discussed by different students from different perspectives, argumentations were richer in content, more thorough in analysis, and more comprehensive in coverage. This co-authoring experience and the social support provided therein, as social constructivists (Burr, 2003; Schwandt, 2003) argue, are more likely to take students to higher levels of achievement than the case with individual performance. Compared to traditional classroom settings often characterized by fragmentation, competition, and degenerative behaviors (Lewis \& Dehler, 2000; Schneider \& Ingram, 2007) reflective blogfolios availed a more cooperative atmosphere that helped students build on one another's ideas and thus resulted in more rounded argumentations.

Explained in terms of Vygotsky's zone of proximal development (cited in Thompson, 2013), collaborative achievement of learners is often higher than individual achievement. This zone of proximal development is the difference between what learners can achieve individually and what they can achieve in collaboration with other students, the latter being always higher than the former. This is consistent with results of similar research pertinent to using blogs in writing-though reflective blogfolios are different in the sense that they provide more collaborative experiences. For example, Kessler et al (2012) cited blogs as being effective in providing collaborative writing experience that positively impacted student performance. Wang (2010) mentioned similar conclusions that the use of online workplace for sharing ideas and coordinating collaboration led to better performance.

Second, the multiplicity of knowledge sources that are available to students online and the ease of access thereof may have contributed to the significant impact of the reflective blogfolios. Pressing a button can flood students with all types of information they might be in need of in their argumentations. Students can access knowledge in different forms, be it print-based, audio, video, textual, graphic, or multimodal sources. All can be hyperlinked, integrated, and posted on the blogfolios in a way that would help learners construct more rounded arguments. This is consistent with conclusions of pertinent language research on virtual learning environments where availability of knowledge sources and the different forms of knowledge available to students therein were key factors behind quality learning performance (Fageeh \& Mecheimer, 2013; De-Rycher, 2011).

Third, reflective blogfolios were effective in creating a community of discourse amongst students. Three aspects characterized this discourse community and contributed to higher levels of engagement and participation. These are communication rationality, collaborative scaffolding, and reader-based writing orientation. Reflective blogfolios provided students with equal chances to participate, negotiate content, argue, and communicate ideas in a more evenlydistributed fashion than the case with face-to-face argumentation that is often governed by rules of communication hierarchy and dominance of vocal learners. Here, communication hierarchy was replaced by communication rationality 
where, as described by Schneider and Ingram (2007), there is no status differentiation amongst students and all have equal chances to share their ideas.

In collaborative scaffolding, vocal students not only gave way to the poor ones to share their ideas, but also provided learning scaffolds to help them overcome their problems and participate more effectively in the argumentative situations (Felton \& Herko, 2004, Thompson, 2013). As students negotiated ideas together, reconciled apparently contradicting views, and provided feedback on one another's work, the writing experience changed into an authentic communication process where students targeted real audience -- fellow members of this online discourse community.

This reader-based writing practice created an ongoing process of authentic interaction. The negotiation and modification of both content and language according to message comprehensibility for the intended audience helped students write more convincing arguments and tune up their ideas and language according to the proficiency levels of those arguing with them. As Karolides (2013) argues, reader-based writing makes sense to the readers and helps individuals respond to others' written work in a constructive and respectful way. This is consistent with conclusions of Janassen et al. (2006), Wang (2010), and Chen and She (2012) that online learning environments can provide excellent support for students to construct their explanations and knowledge negotiation processes in argumentative writing.

Fourth, the diversity of audience students communicated with in their reflective blogfolios is another factor that might have contributed to its effectiveness. Contrary to traditional classroom settings, in reflective blogfolios learners have more chances to interact with individuals coming from different veins of life and are thus more likely to hold varied cultural norms and ways of looking at things. Literature on argumentative writing shows that argumentation mechanisms and the ways individuals approach argumentative tasks differ when differences exist in the composition of the argumentation groups.

For example, Ryan and David (2003) differentiated between in-group and out-group ways of argumentation. Whereas the former refers to argumentation with group members holding similar backgrounds, learning approaches, and similar ways of looking at things, the latter refers to argumentation with individuals who are different in their learning preferences and the way they approach tasks. It seems that the reflective blogfolios experience has helped students deal with both contexts and thus broadened their horizons and equipped them with a richer repertoire of argumentation techniques, ways, and procedures.

Fifth, the ongoing monitoring and reflection process that students practiced throughout the whole reflective blogfolios experience might also have been a determinant factor. Reflective blogfolios provided students with a viable tool for monitoring their argumentative writing performance over an extended period of time and reflecting on their ideas and past learning to see how much improvement has been achieved. As students interacted with peers of varied linguistic levels and background knowledge, they had a chance to position themselves along the proficiency continuum for a closer look at their argumentative writing needs, the way they have gone so far, and that they still have to go. This monitoring and reflection practice and the panoramic view of their argumentative writing development helped them spot their own mistakes and rectify them with the help of peers and the instructor.

Self-regulated learning theorists (Pintrich \& Zusho, 2002; Zimmerman, 2008) consider monitoring and reflection a cornerstone for developing autonomy and self-regulatory behaviors in academic settings and guarding against students derailing from pre-set goals and standards of quality performance. The result, as pertinent research indicates, is more depth in their students' writing (Richardson, 2003), more standard conventions than those who don't write online (Dickey, 2004) and higher levels of grammatical competence due to negotiation over all aspects of discourse (Pelletteri (2005).

Regarding the ways of knowing, three conclusions can be drawn from the results of the current study. The first of these is that argumentative writing capabilities of EFL students are positively correlated with their ways of knowing. This adds yet another factor contributing to excellence in argumentative settings that has not been adequately addressed in EFL writing research. Existing literature on written argumentation of EFL students related the quality of argumentation to a multitude of reasons. For example, Ferretti et al (2009) attributed the quality of argumentative writing to the kind of adopted goals--elaborated vs. general, where elaborated goals are used to refer to more genre-specific argumentation. Graham (2006) related better argumentative writing to direct/explicit strategy instruction.

The current study relates the quality of students' argumentation to the ways of knowing students are likely to employ and how productive these ways of knowing are. Students who used more connected ways of knowing in approaching argumentative issues succeeded in improving their argumentative writing performance. This is consistent with conclusions of pertinent research regarding individuals' stances on argumentative issues. As stated by Nassbaum and Kardash (2005), students with extreme attitudes towards the argumentative issue generated fewer alternative standpoints about the issue than those with less extreme attitudes. "Extreme attitudes" in Nassbaum and Kardash's study are used in a sense similar to the" separate ways of knowing" in the current study.

A second conclusion regarding the ways of knowing in this study relates the issue of stability. Initial work on the ways of knowing was conducted with an implicit assumption that these ways of knowing are stable and non-changing. Later researchers and educators supported the idea that ways of knowing are flexible and context dependent (Ryan \& David, 2003; Feldman et al., 2006; Schneider \& Ingram, 2007). Results of the current study flock with the latter group supporting the view that ways of knowing are flexible and transformable. Yet, transforming these ways of knowing is not an easy task. Rather, as Belenky et al (1997) argue, it is a much deeper process of systemic change that needs 
effective classroom conditions. It seems that reflective blogfolios availed suitable conditions and effective tools for transforming students' ways of knowing in a way that contributed to better argumentative writing performance.

The third conclusion is that the ways of knowing are complementary rather than distinct and that both connected and separate ways of knowing are important in argumentative writing settings. Although initial research assumed that they are distinct with individuals being characterized as either connected or separate knowers (Clinchy, 1996; Belenky et al, 1997), lately researchers and educators (Schommer-Aikins \& Easter, 2006) concluded that most people are capable of both ways of both ways of knowing though some individuals may prefer one way of knowing over the other. The current study further argues that ways of knowing are complementary rather than different and that preference of certain ways of knowing depends on the context rather than being a personal trait.

This proposition is consistent with what is referred to in neuro-linguistic programming as positions of the mind. As explained by Bee and Bee (1998, cited in Szestazy, 2004) "three positions of the mind determine one's responses in learning settings: 'position 1 ' is described as being focused on oneself; 'position 2' as being focused on others, and 'position 3' as having a helicopter view" (P.38). The complementary view of the ways of knowing is the symbolic representation of this panoramic helicopter view. This is also in line with what Miller et al (2008) termed as "epistemological pluralism". In any given context there are several valuable ways of knowing and that accommodating this plurality can lead to more successful study performance. As Miller et al (2008) argue, through incorporating a pluralistic framework, issues can be better explored, resulting in a more integrated understanding.

This leads to the final conclusion regarding ways of knowing in this study. It seems, based on the results of the current study, that connected ways of knowing constitute more epistemologically sophisticated stances and are thus more productive in argumentative settings. Epistemological sophistication, as epistemic researchers argue (Schommer-Aikins \& Easter, 2008; Hofer, 2008), refers to embracing more flexible and adaptive standpoints in educational settings rather than the dichotomous black/white stances. As the results of the study indicate, connected ways of knowing were better predictors of quality argumentative essay writing performance than separate ways of knowing.

Compared to separate knowers, students with connected ways of knowing showed more understanding of opponents' arguments and more tendency to see things from their vantage points, even though they did not identify with their opponents' standpoints. They were able to swing the pendulum back and forth between the two extreme positions in argumentation settings and to exhibit more epistemic pluralism in the sense explained above by Miller et al (2008). The point that is to be stressed here is that connected knowing does not imply giving up own points of view for the sake of others'. Rather, it implies seeing things from others' vantage points and juxtaposing them with own stances for logicality and convincingness as a basis for judging their credibility. This reflects the very notion of the helicopter view cited above.

\section{Implications \& Recommendations}

Results of the current study have a number of implications for writing instruction as well as foreign language instruction in general. It seems from the results of the study that argumentative writing and ways of knowing have a joint vein. The relationship between the two is characterized by reciprocity rather than one-way influence. As the results of the current study indicate, initial ways of knowing impacted the argumentative stances students were likely to adopt. Yet, EFL students' subsequent engagement in argumentation with those differing from them in terms of the ways of knowing led to reframing their very ways of knowing. Since the impact of the ways of knowing might extend to other language skills and language learning settings, study of EFL students' ways of knowing should be a core component in language research, curricula, and classroom practices.

Although the current study is interested in ways of knowing in argumentative writing, implications may also be extended to the language learning context in general, a context that is heavily based on interaction, communication, and negotiation of ideas. Existing practices in most language learning settings focus on separate ways of knowing with little attention to connected practices. When individuals embrace separate ways of knowing, they disregard peers' input and show little empathy for their stances, which in turn increases the likelihood that degenerative learning behaviors prevail. Degenerative behaviors here refer to classroom practices wherein peers' ideas and contributions are falsified, trivialized and refuted in a way that hinders comprehensibility, collective reasoning, and collaboration (Schneider \& Ingram, 2007).

This is particularly important in synchronous, online, e-learning, or other types of learning environments that Siemens (2008) described as connectivist, wherein EFL students are likely to interact with peers coming from different cultural, educational, and social backgrounds. As learners in these connectivist environments might have ways of knowing different from their own, they might of in need of training in how to interact, connect, and manage contradictions in stances and views. Being able to reach compromises, reconcile apparently contradictory stances, and achieving mutual understanding would pay off in terms of better learning outcomes as well as higher levels of adaptability to fluctuations in learning conditions.

The same applies to instructional practices of EFL teachers. Understanding learners' ways of knowing might help teachers better interpret how their learners look at things and thus connect with them more efficiently. This is particularly important for EFL students whose frames of reference, processing mechanisms, and learning experiences are different from those of the teachers. The mismatch between how teachers teach and how their learners learn is likely to result in poor learning attainment. When teachers are cognizant of their students' ways of learning and knowing, they can fine tune their teaching practices to the needs and styles of those learners (Schommer-Aikins \& 
Easter, 2008). Teachers need to connect with learners and see how they perceive whatever knowledge or learning experiences that are conveyed to them.

\section{Suggestions for Further Research}

A number of issues stemming from the results of the current study need further investigation in future research before generalizing these results and conclusions thereof. The first of these issues is that ways of knowing have been related to argumentative writing performance in general. As literature on the writing processes indicates, different processes and stages of writing have different focuses and might thus activate different cognitive processing mechanisms (Seow, 2002; Hedge, 2005). Further research is needed to see if students' ways of knowing change along the different processes of writing, which stages activate what ways, and which ways of knowing are more effective in which writing stages/processes. One would assume that connected ways of knowing be more fruitful in idea generation processes/stages where students are expected to connect with one another, show empathy for peers' stances, mutually build on generated ideas, and reconcile contradictory views. Separate ways of knowing, on the other hand, might be more effective in revising and editing processes where students have to detach themselves from what they might have written and look at their writing with a more critical eye. Further research is needed to verify this assumption.

The second of these issues relates to gender differences in argumentation and ways of knowing. Gender differences in the ways of knowing remain controversial. For example, some researchers (Baron, 2006; Mars \& Benton, 2006) stated that differences between men and women in their ways of knowing do exist, with women scoring higher on connected knowing and men tending more to be separate knowers. Others (Schommer-Ainkins \& Easter, 2006; Gallotti et al, 2001) concluded that the connected and separate knowing scores of men were not significantly different, whereas females typically showed significantly higher connected scores. A third group of researchers (Ryan \& David, 2003) questioned the very notion that ways of knowing are intrinsically related to gender. Further research needs to investigate gender differences in argumentative writing capabilities and how far these differences can be attributed to gender differences in students' ways of knowing- if any.

A third issue that needs due attention in future research is the impact of cultural settings on EFL students' ways of knowing. Existing literature indicates that academic knowledge is organized according to disciplines and fields of knowledge that are grounded in Western ways of knowing and are therefore insensitive to non-Western cultures (Martin et al., 2002; Cargile, 2006). As well, pertinent research on ways of knowing indicates they are context sensitive with all likelihood that different cultural contexts activate different ways of knowing (Hofer, 2008; Liu, 2009). Regarding writing settings, research also shows that cross-cultural variation in text generation and cognitive processes does exist (Schoonen \& Gelderen, 2003; Roca-De-Larios \& Murphy, 2006; Walter, 2011; Eldaly, 2012). Put together, it seems that ways of knowing and writing rituals and techniques are culture-sensitive and need to be considered in non-Western contexts. Future research needs to investigate cultural differences in ways of knowing and how far they can predict variation in argumentative writing performance before generalizing the conclusions of the current study to other cultural contexts of foreign language instruction.

A final point here relates to argumentative writing and ways of knowing in hybrid, blended, virtual, and personal learning environments compared to traditional learning settings. With increased tendencies to shift away from traditional learning to connectivist learning environments (Siemens, 2008), research is needed to compare EFL students' ways of knowing in traditional and virtual learning settings for any possible disparities between the two. When migrating to connectivist learning environments, more often than not teachers carry over their very techniques used in traditional learning environments to the virtual ones. With the likelihood that differences between the two types of learning environments activate different ways of knowing, further research is needed to investigate these possible differences and suggest commensurate instructional practices accordingly.

\section{References}

Almelhi, A. (2014). The effects of teaching argumentative reading and writing by integration in an e-learning environment on literacy development in EFL college students. International Journal of Humanities and Social Studies, 4(5), 85-102.

Ananyeva, M. (2014). Blogfolios and their role in the development or research projects and advanced academic literacy classes for ESL students. Tech Trends, 58(5), 22-26.

Andrews, R. (2009). The importance of argument in education. London: UK Institute of Education.

Andrews, R. (2010). Argumentation in higher education: Improving practice through theory and research. New York: Routledge.

Andrews-Weckerly, S. Ferretti, R. P. \& Lewis, W. E. (2004). Determinants of the quality of arguments written by students with and without learning disabilities. Paper presented at the Annual Pacific Coast Research Conference. San Diego, CA.

Andriessen, J., Baker, M \& Suthrs, D. (2003). Arguing to learn: Confronting cognitions in computer-supported collaborative learning environments. Springer Publishing.

Arsyad, S. (2000). The Indonisian and English argument structure: A cross-cultural rhetoric of argumentative texts. Australian Review of Applied Linguistics, 22(2), 85-102. 
Attwell, G. (2007). Personal learning environment- the future of e-learning? E-learning Papers, 2 (1). ISSN $1887-1542$. Retrieved on June $3^{\text {rd }}$, 2010 from www.elearningpapers.eu.

Barnhardt, R. \& Kawagley, A. (2005). Indigenous knowledge systems and Alaska native ways of knowing. Anthropology and Education Quarterly, 36(10, 8-23.

Barnett, R. (2008) A will to learn: Being a student in an age of uncertainty. Buckingham: Society for Research into Higher Education/Open University Press.

Baron, C. E. (2006). Ways of knowing: A quantitative analysis of the intersection between the Ways of Knowing Model and Perry's Scheme of Intellectual Development. Paper presented at the Adult Education Research Association Conference. Retrieved on June 25 ${ }^{\text {th }}, 2014$ from http://newprairiepress.org/aerc/2006/papers/5.

Belenky, M. F., Clinchy, B. M., Goldberger, N. R. \& Tarule, J. M. (1997). Women's ways of knowing: The development of self, voice and mind. New York: Basic Books.

Boyd. D. (2006). A bloger's blog: Exploring the definition of a medium. Reconstruction, 6(4). Retrieved on June 23, 2014 from http://reconstruction.eserver.org/064/boyd.shtml.

Burr, V. (2003). Social constructionism (2nd ed.). London: Routledge.

Cargile, A. C. (2006). Imagining culture with a little help from the pushmi-pullyu. In L. A. Samovar, R. E. Porter, \& E. R. McDaniel (Eds.), Intercultural Communication (pp. 16-21). Belmont, CA: Thomson/Wadsworth.

Carter, M. (2007). Ways of knowing, doing, and writing. College Composition and Communication, 58(3), $385-418$.

Chatti, M. A. Augustiawan, M. Jarke, M., \& Specht, M. (2010). Toward a personal learning environment framework. International Journal of Virtual and Personal Learning Environments, 1(4), 71-82.

Chen, C. H. \& She, H. C. (2012). The impact of recurrent online synchronous scientific argumentation and conceptual change. Education Technology \& Society, 15(1), 197-210.

Chinn, C. A. (2006). Learning to argue. In A. M. O'Donnel, C. E. Hmelo-Silver \& G. Ertens (Eds.), collaborative learning, reasoning, and technology (pp.355-383). Mahwah, NJ: Erlbaum.

Clinchy, B. (1996). Connected and separate knowing: Toward a marriage of two minds. In N. R. Goldberger, J. M. Tarule, B. Clinchy, \& M. F. Belenky (Eds.), knowledge, difference, and power, (pp. 205-247). New York: Basic Books.

De La Paz, S. (2005). Effects of historical reasoning instruction and writing strategy mastery in culturally and academically diverse middle school classrooms. Journal of Educational Psychology, 97(2), 134-144.

De - Rycher, A. (2011). The effect of online reading on argumentative essay writing quality. GEHA Online Journal of Language Studies, 11(3), 147-161. Retrieved June 10, 2013 from: https://core.ac.uk/download/pdf.

Deatline-Buchman, A. \& Jitendra, A. (2006). Enhancing argumentative essay writing of fourth-grade students with learning disabilities. Learning Disability Quarterly, 29(1), 39-54.

Dickey, M. D. (2004). The impact of web-logs (blogs) on student perceptions of isolation and alienation in a web-based distance-learning environment. Open Learning, 19(3), 279-291.

Ebner, M. (2009). Introducing live micro-blogging: How single presentations can be enhanced by the mass. Journal of research in innovative teaching, 2(1), 108 - 119.

Eldaly, H. (2012). Cross-cultural and cognitive variation in the persuasive writing of Arabic and Spanish speakers: A qualitative analysis. International Journal of Academic Research in Business and Social Studies, 2(7), 51-81.

Facione, P. (2009). Critical thinking. California: California Academic Press.

Fageeh, A. \& Mekheimer, M. (2013). Effects of Blackboard on EFL academic writing and attitudes. The JALTCALL Journal, 9(2), 169-196.

Fahim, M. \& Hashtroodi, P. (2012). The effect of critical thinking on developing argumentative essays by Iranian EFL university students. Journal of Language Teaching and Research, 3(4), 623-638.

Feldman, M. S., Khademian, A. M., Ingram H., \& Schneider, A. L. (2006). Ways of knowing and inclusive management practices. Public Administration Review.66, 89-99.

Felton, M. K. \& Herko, S. (2004). From dialogue to two-sided argument: Scaffolding adolescents' persuasive writing. Journal of Adult and Adolescent literary, 47(8), 672-683.

Ferretti, R. Andrews-Weckerly, S. \& Lewis, W. (2007). Improving the argumentative writing of students with learning disabilities: Descriptive and normative considerations. Reading and Writing Quarterly, 23, 267-285.

Ferretti, R. Lewis, W. \& Andrews-Weckerly, S. (2009). Do goals affect the structure of students' argumentative writing strategies? Journal of Educational Psychology, 101(3), 577-589.

Galotti, K. M., Reimer, R. L. \& Drebus, D. W. (2001). Ways of knowing as learning styles: Learning MAGIC with a partner. Sex Roles, 44(7/8), 419-436.

Graham, S (2006). Strategy instruction and the teaching of writing: A meta-analysis. In C.A. MacArthur, S. Graham \& J. Fitzgerald (Eds.), Handbook of writing research (pp. 187-207). New York: Guilford Press. 
Graham, S. \& Perin, D. (2007). A meta-analysis of writing instruction for adolescent students. Journal of Educational Psychology, 99(3), 445-476.

Grami, M. (2012). Online collaborative writing for ESL students using blogs and feedback checklists. English Language Teaching, 5(10), 43-48.

Hall, R. (2009). Towards a fusion of formal and informal learning environments: The impact of the Read/Write Web. Electronic Journal of E-learning, 7 (1), 29-40. Retrieved on May 25, 2013 from www.ejel.org.

Hedge, T. (2005). Writing. Oxford: Oxford University Press.

Herring, S. C., Scheidt, L. A., Bonus, S. \& Wright, E. (2004). Bridging the gap: A genre analysis of weblogs. Proceedings of the 37th Hawai'i International Conference on System Sciences. Los Alamitos: LEEE Computer Society press.

Hirose, K. (2003). Comparing L1 and L2 organizational patterns in the argumentative writing of Japanese EFL students. Journal of Second Language Writing, 12, 181-209.

Hofer, B. K. (2008). Personal epistemology and culture. In M. S. Khine (Ed.), Knowing, knowledge and beliefs: Epistemological studies across cultures (pp. 3 - 22). Dorchert, the Netherlands: Kluwer Academic Publishers.

Jonassen, D. H., \& Kim, B. (2010). Arguing to learn and learning to argue: Design justifications and guidelines. Educational Technology Research and Development, 58(4), 439-457.

Kachru, Y. (2005). Culture and argumentative writing in world Englishes. In K. Bolton \& B. Kachru (Eds.), World Englishes: Critical concepts in linguistics (pp.19-36). Abingdon: Routledge.

Karolides, N. (2013). Reader response in secondary and college classrooms. New York: Routledge.

Kessler, G., Bikowski, D. \& Boggs, J. (2012). Collaborative writing among second language learners in academic webbased projects. Language Learning and Technology, 16(1), 91-109.

Khine, M. (Ed.) (2008). Knowing, knowledge and beliefs: Epistemological studies across cultures. Dorchert, the Netherlands: Kluwer Academic Publishers.

Khine, M. \& Hayes, B. (2010). Investigating women's ways of knowing: An exploratory study in the UAE. Issues in Educational Research, 20(2), 105-117.

Knight, K., Elfinbein, M. \& Messina, J. (1995). A preliminary scale to measure connected and separate knowing: The knowing scale inventory. Sex Roles, 33(7/8), 449-513.

Kolour, D. (2015). The impact of teaching critical thinking tasks on coherence in argumentative essay writing among EFL learners. Mediterranean Journal of Social Sciences, 6(7), 460-468.

Lee, S. H. (2008). An integrative framework for the analyses of argumentative/persuasive essays from an interpersonal perspective. Journal of Text and Talk, 28(2), 239-270.

Lewis, M. W. \& Dehler, G. E. (2000). Learning through paradox: A pedagogical strategy for exploring contradictions and complexity. Journal of Management Education, 26, 708-725.

Lin, H. T., Kuo, T. \& Yuan, S. (2007). A web-based learning portfolio framework built on blog service. Information Technology Journal, 6(6), 858-864.

Liu, X., Magjuka, R., Bonk, C. \& Lee, S. (2007). Does sense of community matter? An examination of participants' perceptions of building leaning communities in online courses. Quarterly Review of Distance Education, 8(1), 9-24.

Liu, Y. (2009). The impact of cultural factors on Chinese and American college students' rhetoric choices in argumentative discourse: A contrastive study. Intercultural Communication Studies, XVIII (1), 128-142.

Maftoon, P., Birjandi, P. \& Pahlavani, P. (2014). The impact of using computer-aided argumentative writing mapping on the improvement of writing achievement of Iranian learners of English. Theory and Practice in Language Studies, 4(5), 982-988.

Mars, H., \& Benton, S. (2009). Relationships between separate and connected knowing and approaches to learning. Sex Roles, 60, 57-66.

Martin, J. N., Nakayama, T. K., \& Flores, L. A. (2002). A dialectical approach to intercultural communication. In J. N. Martin, T. K. Nakayama, \& L. A. Flores (Eds.), Readings in intercultural communication: Experiences and contexts $\left(2^{\text {nd }}\right.$ ed.) (pp. 3-13). Boston: McGraw-Hill.

Mason, R. \& Rennie, F. (2007). Using web 2.0 for learning in the community. The Internet and Higher Education, 10(3), 196-203.

Miller, T. R., Baird, T. D. Littlefield, C. M. Kofinas, G. \& Redman, C. I. (2008). Epistemological pluralism: Reorganizing interdisciplinary research. Ecology \& Society, 13(2), 46. Retrieved on May 12, 2013 from http://www.ecologyandsociety.org/vol13/15s2/art46.

Nussbaum, M. E. \& Kardash, C. (2005). The effects of goal instructions and text on the generation of counterarguments during writing. Journal of Educational Psychology, 97, 157-169.

Nassbaum, M. E. \& Schraw G. (2007). Promoting argument-counterargument integration in students' writing. Journal of Experimental Education, 76(1), 59-93. 
Osborne, J. (2010). Arguing to learn in science: The role of collaborative critical discourse. Science, 823, 463-466.

Osborne, J., Erduran, S., \& Simon, S. (2004). Enhancing the quality of argumentation in school science. Journal of Research in Science Teaching, 4(10), 994-1020.

Palloff, R. M. \& Pratt, K. (2005). Collaborating online: Learning together in community. San Francisco: Jossey-Bass.

Pearson, E., Gkatzidou, V. \& Green, S. (2009). A proposal for an adaptable personal learning environment to support learners needs and preferences. In same places, different spaces. Proceedings of Ascilite, Aukland, 2009. Retrieved from http://www.ascilite.org.au/conferences/aukland2009/procs/pearson.pdf, on May 25, 2013

Pelletteri, J. (2005). Negotiation in cyberspace: the role of chatting in the development of grammatical competence. In M. Warschauer \& R. Kern (Eds.), Network-based language teaching: Concepts and practice (3 ${ }^{\text {rd }}$ ed.). Cambridge: Cambridge University Press.

Perloff, R. M. (2003). The dynamic of persuasion (2nd ed.) Mahwah, NJ: Erlbaum.

Pintrich, P. R. \& Zusho, A. (2002). The development of academic self-regulation: The role of cognitive and motivational factors. In A. Wigfield \& J. Eccles (Eds.), The development of achievement motivation (pp. 250-279). San Diego, CA: Academic Press.

Richardson, W. (2003). Weblogs in the English classroom: More than just chat. English Journal, 93(1), 39-43.

Roca De Larios, J. R. \& Murphy, I. (2006). Generating text in native and foreign language writing: A temporal analysis of problem solving formation process. The Modern Language Journal, 90, 100-114.

Ryan, M. \& David, B. (2003). Gender differences in ways of knowing: The context dependence of the attitudes toward thinking and leaning survey. Sex Roles, 49(11/12), 693-699.

Sayed, S. (2012). Formative assessment: Uncovering writing excellence one student at a time. In C.L. Gunn (Ed.). Enhancing teaching and learning in higher education in the United Arab Emirates: Reflections from the classroom. London: Cambridge Scholars Publishers.

Schellen, P. \& De Jong, M. (2004). Argumentation schemes in persuasive brochures. Argumentation, 18, 295 -323.

Schneider, A. \& Ingram, H. (2007). Ways of knowing and public policy. Paper presented at the Annual Meeting of the American Political Science Association, Chicago, August 29-September 2. Retrieved on May 25, 2014 from http://citeseerx.ist.psu.edu/viewdoc/download.

Schommer-Aikins, M. (20040. Explaining eh epistemological belief system: Introducing the embedded systemi model and coordinated research approach. Educational Psychologist, 39(1), 19-29

Schommer-Aikins, M. \& Easter, M. (2006). Ways of knowing and epistemological beliefs: Combined effects on academic performance. Educational Psychology, 26(3), 411-423.

Schommer-Aikins, M. \& Easter, M. (2008). Epistemological beliefs' contributions to study strategies of Asian Americans and European Americans. Journal of Educational Psychology, 4, 920-929.

Schoonen, R. \& Golderen, A. (2003). First language and second language writing: The role of linguistic knowledge, speed of processing, and metacognitive knowledge. Language Learning, 5(3), 165-202.

Schwandt, T. A. (2003). Three epistemological stances for qualitative inquiry: Interpretativism, hermeneutics, and social constructionism. In N. Denzin \& Y. Lincoln (Eds.), The landscape of qualitative research: Theories and issues (pp.292-331). CA: Sage Publication.

Schwarz, B. B., Neuman, Y., Gil, J. \& Iiya, M. (2003). Construction of collective and individual knowledge in argumentative activity. Journal of the Learning Sciences, 12, 219-256.

Seow, A. (2002). The writing process and the process writing. In J. C. Richards \& W. A. Renandya (Eds.), Methodology in language teaching: An anthology of current practice (pp.315-320). New York: Cambridge University Press.

Shanahan, T. (2004). Overcoming dominance of communication. Writing to think and to learn. In T.L. Jetton \& J.A. Dole (Eds.). Adolescent Research and Practice (pp.59-73). New York: Guilford.

Shea, P. (2006). A study of students' sense of learning community in online environments. Journal of Asynchronous Learning Networks, 10(1), 35-44.

Siemens, G. (2008). New structures and spaces of learning: The systemic impact of connective knowledge, connectivism, and networked learning. Retrieved on May, 25, 2013 from http://elearnspace.org/articles/systemic_impact.htm.

So, H. J. \& Brush, T. A. (2008). Student perceptions of collaborative learning, social presence, and satisfaction in a blended learning environment: Relationships and critical factors. Computer \& Education, 51(1), 318-336.

Stylinger, M. \& Overstreet, J. (2014). Strengthening argumentative writing with speaking and listening (Socratic) circles. Voices from the Middle, 22(1), 58-62.

Szestazy, M. (2004). Teachers' ways of knowing. ELT Journal, 58(2), 129-136. 
Targhi, B., Ebner, M. \& Kroell, C. (2012). Personal learning environment - generation 2.0. In T. Amiel \& B. Wilson (Eds.), Proceedings of World Conference on Educational Multimedia, Hypermedia and Telecommunications 2012 (pp. 1828-1835). Chesapeake, VA: AACE.

Thompson, I. (2013). The mediation of learning in the zone of proximal development through a co-constructed writing activity. Research in the Teaching of English, 47(3), 247-276.

Valsiner, Jaan (2006). Dangerous curves in knowledge construction within psychology: Fragmentation of methodology. Theory \& Psychology, 16(5), 597-612.

Van-Eemeren, F. H. \& Grootndorst, R. (2004). A systematic theory of argumentation: The pragma-dialectical approach. Cambridge: Cambridge University Press.

Walter, J. (2011). Variation in the language linguistic systems. London: Routledge.

Wang, Q. (2010). Using online shared workspaces to support group collaborative learning. Computer \& Education, 55, $1270-1276$.

Wingate, U. (2011). Argument! Helping students understand what essay writing is about. Journal of English for Academic Purposes, 10(2), 89-101.

Yang, H. H. (2006). Blogfolios for student-centered reflection and communication. In M. Iskander (Ed.), Innovative techniques in instruction technology, E-learning, E-assessment, and Education (pp. 179-182). Netherlands: Springer.

Yuen, S. C. \& Yang, H. (2010). Using blogfolios to enhance interaction in E-learning courses. In S. Yuen, \& H. Yang (Eds.), Handbook of research on practices and outcomes in E-learning: Issues and trends (pp. 455-470). Hershey: Information Science Reference.

Zimmerman, B. (2008). Investigating self-regulation and motivation: Historical background, methodological developments, and future prospects. American Educational Research Journal, 45(1), 166-183.

Zohar, A. \& Nemet, F. (2002). Fostering students' knowledge and argumentation skills through dilemmas in human genetics. Journal of Research in Science Teaching, 39(10, 35-62. 